\title{
Low practice of malaria prevention among migrants and seasonal farmworkers in Metema and west Armacheho districts, Northwest Ethiopia
}

Getu Debalkie Demissie ${ }^{1 *}\left(\mathbb{D}\right.$, Tadesse Awoke Ayele ${ }^{2}$, Sintayehu Daba Wami ${ }^{3}$, Malede Mequanent Sisay ${ }^{2}$, Destaw Fetene ${ }^{2}$, Haileab Fekadu Wolde², Temesgen Yihunie Akalu² and Kassahun Alemu Gelaye ${ }^{2}$

\begin{abstract}
Background: More than hundreds and thousands of migrants and seasonal farm workers move from the highlands (relatively low malaria endemicity areas) to the lowlands (higher malaria endemicity areas) for the development of the corridor of the Amhara region during planting, weeding, and harvesting seasons in each year. Seasonal migrant workers are at high risk of malaria infection. Therefore, evidence of their knowledge level and practice in the prevention of malaria during their stay would be important.

Objective: The aims of this study was to assess the knowledge and practice of malaria prevention and associated factors among migrants and seasonal farm workers in Northwest Ethiopia.

Method: A cross-sectional study was conducted from October to November, 2018 in Metema and West Armacheho districts, northwest Ethiopia. A sample of about 950 migrants and seasonal farm workers were included using two stages of cluster sampling technique. Interview administered structured questionnaire was used. Both bivariable and multivariable binary logistic regressions were applied to identify predictors of malaria prevention.

Result: The overall good knowledge of malaria (those participants who scored more than $60 \%$ of correct response for knowledge related questions) was $50.2 \%$ with $95 \% \mathrm{Cl}(47.0-53.0)$ and the overall good practice of malaria (those participants who practiced more than $60 \%$ for practice related questions) was $27.2 \%$ with $95 \% \mathrm{Cl}(244.3-29.9)$. Age $(A O R=0.51(95 \% \mathrm{Cl} ; 0.33-0.80))$, level of education $(A O R=0.55(95 \% \mathrm{Cl} ; 0.32-0.94))$, using mass media as a source of information ( $\mathrm{AOR}=2.25(95 \% \mathrm{Cl} ; 1.52-3.32))$ and length of stay at the farming site $(\mathrm{AOR}=0.59(95 \% \mathrm{Cl} ; 0.44-0.79))$ were significantly associated with knowledge of malaria prevention. Knowledge ( $A O R=6.62(95 \% \mathrm{Cl} ; 4.46-9.83))$, attitude (AOR $=2.17(95 \% \mathrm{Cl} 1.40-3.37)$, use of mass media ( $\mathrm{AOR}=1.64(95 \% \mathrm{Cl} ; 1.30-2.60)$ ) and the length of stay $(A O R=1.93(95 \% C l ; 1.35-2.77))$ in the farming area were significantly associated with practice of malaria prevention.

Conclusion: The practice of malaria prevention among migrant and seasonal farm workers was low. The programmers and implementers should design tailored malaria intervention programs and strategies for these hard to reach population.
\end{abstract}

Keywords: Knowledge, Practice, Attitude, Malaria, Migrant and seasonal farm workers

\footnotetext{
*Correspondence: getud2006@gmail.com

'Department of Health Education and Behavioral Science, Institute of Public Health, University of Gondar, Gondar, Ethiopia

Full list of author information is available at the end of the article
}

(C) The Author(s). 2021 Open Access This article is licensed under a Creative Commons Attribution 4.0 International License, which permits use, sharing, adaptation, distribution and reproduction in any medium or format, as long as you give appropriate credit to the original author(s) and the source, provide a link to the Creative Commons licence, and indicate if changes were made. The images or other third party material in this article are included in the article's Creative Commons licence, unless indicated otherwise in a credit line to the material. If material is not included in the article's Creative Commons licence and your intended use is not permitted by statutory regulation or exceeds the permitted use, you will need to obtain permission directly from the copyright holder. To view a copy of this licence, visit http://creativecommons.org/licenses/by/4.0/ The Creative Commons Public Domain Dedication waiver (http://creativecommons.org/publicdomain/zero/1.0/) applies to the data made available in this article, unless otherwise stated in a credit line to the data. 


\section{Introduction}

World Health Organization (WHO) reported that 3.2 billion people remained at risk of malaria in 2016. In the same report, globally, there were 212 million malaria cases and 4 million deaths, of which $92 \%$ were in African region [1]. Malaria is placed a leading communicable disease in Ethiopia, accounting for about 30\% of the overall DALY (Disability Adjusted Life Years) lost [2].

Recent studies have shown that history of travel is a risk factor for malaria in some parts of Ethiopia [3, 4]. Migrant and seasonal farmworkers (MSFWs) are one of the high risk groups for malaria [5]. The Government of Ethiopia recommended to take weekly mefloquine administered at $5 \mathrm{mg} / \mathrm{kg}$ drug for chemoprophylaxis for non-immune travelers who visit malarias areas for a period of 2-3 month. Chemoprophylaxis should be started 2 weeks before departure and 4 weeks after return from the malaria risk areas [6].

In each year, an estimated 400,000-500,000 MSFWs move from the highlands (relatively low malaria endemicity areas) to the lowlands (higher malaria endemicity areas) of Amhara region (Ethiopia) during planting, weeding, and harvesting seasons. Metema and West Armacheho (the largest scale agricultural farming area in the region) accounted for $20.9 \%$ of all confirmed malaria cases from the Amhara region, and the prevalence of malaria in this region is $12 \%$ [7].

MSFWs perform their daily activities based on a contract basis. As a result, they work for a long hours including nightfall. This working conditions expose them for malaria mosquito's bite. They are also at risk of bringing malaria infection back to their home communities [8]. It was discovered that untreated malaria could result into hepatomegaly, splenomegaly, varying degree of anemia and various syndromes resulting from the involvement of individual organs [9].

Although the knowledge and practice of malaria prevention play a significant role to prevent malaria, there are limited studies which explains the knowledge and practice of malaria prevention among migrant and seasonal farm workers.. Therefore, the aim of this study was to assess the knowledge and practice of malaria prevention and associated factors among MSFWs in Metema and West Armacheho districts, northwest Ethiopia which in turn provides evidences for the programmers and implementers to consider these population in designing malaria elimination intervention strategies.

\section{Methods}

\section{Study design and setting}

A cross-sectional study was conducted from October to November 2018. The study was conducted in Metema and West Armacheho districts, northwest Ethiopia which are some of the fertile agricultural areas with a large scale of the farming of cash crops in the Amhara region. As a result, hundreds and thousands of migrants and seasonal farm workers travelled to these areas to work, especially in the weeding and harvesting seasons. The area is endemic with malaria, and seasonal farm workers are most affected [10].

\section{Study participants, sample size and sampling procedure}

The source population were all migrant and seasonal farm workers who move to these farming areas for temporary farming work. A sample of about 950 migrants and seasonal farm workers participated in the study using two stages of clustered sampling technique. Pilot study was conducted among 50 migrants and seasonal farm workers in Quara district, West Gondar zone to determine the minimum sample size.

The sample size was determined using single population proportion formula by using the following assumptions. According to the pilot study, the proportion of knowledge and practice were 44 , and $34 \%$, respectively. The assumption were $95 \%$ level of confidence, $5 \%$ margin of error, design effect of 2 and $5 \%$ non-response rate.

Since the sampling technique was cluster, design effect of 2 was used so that the total sample size of 804, and 702 was calculated for knowledge and practice respectively. The sample size was also computed for predictors of health information $(\mathrm{OR}=1.7)$, occupation $(\mathrm{OR}=1.5)$ and favourable attitude $(\mathrm{OR}=1.92)$ with the assumptions of power, 80 and $95 \% \mathrm{CI}$ and the sample size were 976 , 870 and 648 respectively. Finally, the largest sample size of 976 was used.

There were 174 farm sites in the two districts. The average number of migrant and seasonal laborers in each farm is estimated to be 460. In the first stage of sampling, primary sample units (PSUs) were formed by segmenting the farm sites so that each PSU would include approximately 460 migrant and seasonal farm workers. A total of 174 PSUs was formed; of these, 14 farms/PSUs were referred to as "study sites", and they were selected by lottery method. The required study participants from each study site was determined by systematic random sampling.

\section{Data collection and procedures}

Piloted and Interview administered structured questionnaire was used. The questionnaire was developed from different literatures and administered through face to face interview. The interview was conducted by $10 \mathrm{BSc}$ degree trained data collectors. The questionnaire included socio demographic characteristics of the participants, knowledge, practice and treatment seeking behavior related questions to malaria which were developed from different literatures. The questionnaire employed 30 items for knowledge with "yes" and "no 
"which were used to elicit information on knowledge of malaria transmission, preventive strategies and sign and symptom of malaria disease. The questionnaire also included 5 items for the practice of the preventive strategies with "yes" and "no "and 5 items for attitude with likert scale.

The instrument was drafted in English, and it was translated to Amharic. It was also translated back to English by language experts. Besides, a pilot study was conducted. A 2 day training was given to all data collectors and supervisors before the data collection.

\section{Operational definition of terms}

Migrant and seasonal farmworker was defined as individuals who are required to be absent from a permanent place of residence for the purpose of seeking employment in agricultural work. "Good Knowledge" was defined as those participants who scored more than $60 \%$ of correct response for knowledge related questions. "Good practice" was defined as those participants who practiced more than $60 \%$ for practice related questions. "Favorable attitude" was defined as those participants who had positive attitude towards $60 \%$ of attitude related questions [11].

\section{Data analysis}

Epi- data version 3.1 was used to enter the data and STATA version 12 was used for data analysis. Descriptive statistics including frequency distributions and tables were used to present the characteristics of the data. Bi-variable and multivariable binary logistic regressions were applied to determine the association between variables and the two different outcomes (good knowledge and good practice) in each logistic regression model. Variables which were found to have an association at $p$ value $\leq 0.2$ with the dependent variable were entered into multivariable logistic regression for controlling the possible confounding effect. Finally, the variables were taken as significant by considering $5 \%$ level of significance. Adjusted odds ratio (AOR) with its respective $95 \% \mathrm{CI}$ was reported to measure strength of association.

\section{Results}

\section{Socio-demographic characteristics of participants}

Out of the 976 migrant and seasonal farm workers, 950 of them completed the questionnaire with response rate of $97.3 \%$. The mean age of the participants was 26 (SD: 7.82 ) years, in which most of them $(96.6 \%)$ were from Amhara region. About 406 (42.7\%) of the participants were unable to read and write and as $672(70.7 \%)$ of them were farmers. Nearly one in three $(30.8 \%)$ of the participants visited the farming area 2-4 times (Table 1).

\section{Source of Health information}

From the participants, $59.6 \%$ heard information related to malaria. Of these, $53.8 \%$ got the information from health workers, $34.5 \%$ from mass media and $28.4 \%$ from their friends.

\section{Knowledge of migrant and seasonal farmworkers about malaria}

The overall good knowledge about malaria was $50.2 \%$. From the participants, 79.2 and $73.8 \%$ of them mentioned mosquito bite as mode of transmission and risk factor for malaria respectively. The majority of the study participants mentioned sleep under ITN (Insecticide treated nets) as malaria prevention method followed by fill stagnant water. Fever, chills and rigor were the most frequently mentioned sign and symptom of malaria by the study participants (Table 2).

\section{Practice of malaria prevention and treatment seeking behavior}

Of the participants, 258(27.2\%) of them had good practice of different malaria prevention strategies. From these, only $11 \%$ of them used chemoprophylaxis and $20.7 \%$ of them utilized ITN in the last night. Only $214(22.5 \%)$ have ITN and from this, only $14 \%$ of the farmworkers received their ITN from a government mass distribution. The major reason for not utilizing ITNs was lack of accessibility (41\%). Of the participants, $824(86.7 \%)$ of them have ever had malaria in the working area. From these participants who ever had malaria, $649(78.8 \%)$ had no treatment seeking behavior and $559(67.8 \%)$ of them had gone to get health services in serious stage of the diseases.

\section{Factors associated with good Knowledge about malaria}

The overall knowledge about malaria prevention was $50.2 \%$ with $95 \%$ CI (47-53\%). The odds of having good knowledge is decreased by $41 \%$ among participants who lived less than 2 months in the farming area as compared with participants who lived more than 2 months. The odds of having good knowledge is increased by 2.25 times among participants who had media exposure as source of information for malaria than their counter parts (Table 3).

\section{Factors associated with good practice to prevent malaria}

The overall good practice for malaria prevention was $27.2 \%$ with $95 \%$ CI $(24.4 \% .3-29.9 \%)$. The odds of having good practice increased by 1.93 times among participants who lived less than 2 months in the farming area as compared with participants who lived more than 2 months. Study participants who had media exposure as source of information had 1.64 times good practice in 
Table 1 Socio-demographic characteristics of seasonal migrant farmworkers in Metema and West Armacheho districts, Northwest Ethiopia, 2018 $(n=950)$

\begin{tabular}{|c|c|c|}
\hline Variable & Frequency & Percentage \\
\hline \multicolumn{3}{|l|}{ Region } \\
\hline Amhara & 918 & 96.6 \\
\hline Tigray & 27 & 2.9 \\
\hline Oromia & 5 & 0.5 \\
\hline \multicolumn{3}{|l|}{ Sex } \\
\hline Male & 943 & 99.3 \\
\hline Female & 7 & 0.7 \\
\hline \multicolumn{3}{|l|}{ Age } \\
\hline $13-20$ & 244 & 25.7 \\
\hline $21-29$ & 485 & 51.0 \\
\hline $30-39$ & 151 & 15.9 \\
\hline $40-67$ & 70 & 7.4 \\
\hline \multicolumn{3}{|l|}{ Level of education } \\
\hline Unable to read and write & 374 & 39.4 \\
\hline able to read and write & 73 & 7.7 \\
\hline primary & 406 & 42.7 \\
\hline secondary and above & 97 & 10.2 \\
\hline \multicolumn{3}{|l|}{ Occupation } \\
\hline Farmers & 672 & 70.7 \\
\hline student & 177 & 18.6 \\
\hline unemployed & 101 & 10.7 \\
\hline \multicolumn{3}{|l|}{ Family size } \\
\hline $1-2$ & 88 & 9.3 \\
\hline $3-5$ & 536 & 56.0 \\
\hline $6-14$ & 326 & 34.7 \\
\hline \multicolumn{3}{|l|}{ Residence } \\
\hline Rural & 832 & 87.6 \\
\hline Urban & 118 & 12.4 \\
\hline \multicolumn{3}{|l|}{ Religion } \\
\hline Orthodox & 932 & 98.1 \\
\hline Others & 18 & 18.9 \\
\hline \multicolumn{3}{|l|}{ Marital status } \\
\hline Married & 301 & 31.7 \\
\hline Non-married & 649 & 68.3 \\
\hline \multicolumn{3}{|l|}{ Income (daily as MSFWs) } \\
\hline Low & 495 & 52.1 \\
\hline High & 455 & 47.9 \\
\hline \multicolumn{3}{|l|}{ No of visit } \\
\hline 1 time & 178 & 18.7 \\
\hline $2-4$ & 293 & 30.8 \\
\hline $5-8$ & 281 & 29.6 \\
\hline 9-30 & 198 & 20.9 \\
\hline
\end{tabular}

Table 1 Socio-demographic characteristics of seasonal migrant farmworkers in Metema and West Armacheho districts, Northwest Ethiopia, 2018( $n=950)$ (Continued)

\begin{tabular}{|c|c|c|}
\hline Variable & Frequency & Percentage \\
\hline \multicolumn{3}{|l|}{ Length of stay } \\
\hline Less than 2 months & 576 & 60.3 \\
\hline More than 2 months & 374 & 39.7 \\
\hline
\end{tabular}

malaria prevention activities than their counter parts. (Table 4).

\section{Discussion}

The main aim of this study was to determine the knowledge and practice of malaria prevention and associated factors among migrant and seasonal farm workers. The results of this study showed that half and almost one fourth of the participants had good knowledge and practice respectively. Age, level of education, the length of stay in the farming area and mass media as a source of information about malaria were significantly associated with the knowledge and practice of malaria prevention.

This study showed that, $59.6 \%$ of the participants ever heard malaria related information from different sources. This finding was different from a study conducted in the same districts before 5 years, which showed $94.7 \%$ participants reported that they have heard of malaria [12]. This shows that there were different migrant and seasonal farm workers who visit the farming area from year to year. This finding is also by far different from a study conducted in Shewa Robit and Arbaminch zuria districts (Ethiopia) among general population, which showed that almost all the study respondents had ever heard of malaria $[13,14]$. This finding was also lower than a study conducted in Western Cambodia [15]. This indicates that there is huge gap on malaria related information among migrant and seasonal farm workers in Ethiopia, which should be provided continuously at the departure and farming sites these population.

The present study revealed that the majority of the study participants were aware of major signs and symptoms of malaria (fever and headache), and mosquito bite causes malaria. However, only half of the study participants had an overall good knowledge about malaria prevention and control methods. This finding is different from a study conducted in Guarage zone (Ethiopia) among households, which showed that $86 \%$ of the participants had good knowledge on malaria prevention methods [16]. It is also by far lower than a study conducted in Woreta (Ethiopia), which showed that 95.8\% of the study participants had knowledge of malaria transmission and prevention methods [17]. This indicates that malaria education is very low for these groups of population. Migrant and seasonal farmworkers are 
Table 2 Knowledge of participants about malaria in Metema and West Armacheho, Northwest Ethiopia, $2018(n=950)$

\begin{tabular}{|c|c|c|}
\hline Mode of transmission & Frequency (yes) & Percentage \\
\hline Mosquito bite & 752 & 79.2 \\
\hline Blood transfusion & 114 & 12 \\
\hline Mother to child & 62 & 6.5 \\
\hline \multicolumn{3}{|l|}{ Risk factors } \\
\hline Dirty and stagnant water & 701 & 73.8 \\
\hline Seasonal change & 657 & 69.2 \\
\hline Infected mosquito bite & 527 & 55.7 \\
\hline \multicolumn{3}{|l|}{ Prevention methods } \\
\hline Sleep under ITN & 728 & 76.6 \\
\hline Use mosquito repellant & 385 & 40.5 \\
\hline Avoid mosquito bites & 390 & 41 \\
\hline Take prophylaxis & 200 & 21 \\
\hline Spray house with insecticide & 428 & 45 \\
\hline Cut the grass around the house & 541 & 57 \\
\hline Fill in puddles (stagnant water) & 557 & 58.6 \\
\hline Keep house and its surroundings clean (clay, pot, leaves, ...) & 507 & 53.4 \\
\hline Put mosquito screens on the windows & 324 & 34 \\
\hline \multicolumn{3}{|l|}{ Sign and symptom } \\
\hline Fever & 821 & 86 \\
\hline Headache & 793 & 83.5 \\
\hline Nausea & 531 & 55.9 \\
\hline Vomiting & 557 & 58.6 \\
\hline Chills and rigor & 840 & 88.4 \\
\hline Loss of appetite & 689 & 72.5 \\
\hline Body ache or joint pain & 734 & 77.3 \\
\hline Excessive sweeting & 529 & 55.7 \\
\hline Body weakness & 639 & 77.3 \\
\hline
\end{tabular}

vulnerable groups for different diseases; at disproportionate risk of disease compared to non-migrant groups due to differences in social, economic, environmental, and institutional factors [18].

This study also showed that educational status was associated with the knowledge of malaria prevention methods. Participants whose educational status was secondary school and beyond had more knowledge about malaria. This finding is consistent with other studies conducted in Tigray (Ethiopia) and Kenya [19, 20]. This shows the importance of using different health communication strategies to deliver health education about malaria for the targeted group based on their educational status.

Length of stay in the farming area is another variable which was significantly associated with the knowledge and practice of the participants. The reasons might be those migrant and seasonal farm workers who passed more months at the farming areas become familiar with malaria messages, and this results in ignorance and loose motivation to practice malaria prevention strategies.

Age is also significantly associated with both knowledge and practice of malaria prevention. This finding is consistent with other studies [21,22]. This might be because of the fact that as age increase, the exposure for knowledge and practice of malaria prevention also increase, but it does not mean that always true and scientific. Therefore, even if we need to give priorities for adolescent ages of these population, all age group of these population should be addressed with malaria prevention education programs.

This study revealed that only $27.2 \%$ of the participants had good practice in the prevention of malaria. Moreover, ITN utilization was only $20.74 \%$. In fact, this was greater than a study which was conducted in the same districts before 5 years that showed only $8.9 \%$ of the participants used ITNs [12]. Even if the finding shows improvement of ITNs utilization comparing to previous 
Table 3 Factors associated with good knowledge about malaria among seasonal and migrant farmworkers in Metema and West Armacheho districts, Northwest Ethiopia, 2018

\begin{tabular}{|c|c|c|c|c|}
\hline \multirow[t]{2}{*}{ Variables } & \multicolumn{2}{|c|}{ Knowledge status } & \multirow{2}{*}{$\begin{array}{l}\text { COR with } \\
95 \% \mathrm{Cl}\end{array}$} & \multirow{2}{*}{$\begin{array}{l}\text { AOR with } \\
95 \% \mathrm{Cl}\end{array}$} \\
\hline & Good & Poor & & \\
\hline \multicolumn{5}{|l|}{ Age } \\
\hline $21-29$ & 250 & 235 & 1 & 1 \\
\hline $13-20$ & 103 & 141 & $0.69(0.50-0.94)$ & $0.66(0.46-0.95)^{*}$ \\
\hline $30-39$ & 91 & 60 & $1.43(0.98-2.06)$ & $1.28(0.82-2.00)$ \\
\hline $40-67$ & 33 & 37 & $0.84(0.50-1.38)$ & $0.88(0.49-1.58)$ \\
\hline \multicolumn{5}{|l|}{ Level of education } \\
\hline Unable to read and write & 164 & 210 & $0.44(0.28-0.70)$ & $0.55(0.32-0.94)^{*}$ \\
\hline Able to read and write & 44 & 29 & $0.86(0.46-1.60)$ & $0.90(0.44-1.85)$ \\
\hline Primary & 207 & 199 & $0.59(0.37-0.93)$ & $0.70(0.42-1.16)$ \\
\hline Secondary and above & 62 & 35 & 1 & 1 \\
\hline \multicolumn{5}{|l|}{ Family size (in number) } \\
\hline $1-2$ & 49 & 39 & 1 & 1 \\
\hline $3-5$ & 280 & 256 & $0.87(0.54-0.37)$ & $1.10(0.66-1.83)$ \\
\hline $6-14$ & 148 & 178 & $0.66(0.41-1.06)$ & $0.89(0.52-1.51)$ \\
\hline \multicolumn{5}{|l|}{ Marital status } \\
\hline Non-married & 307 & 342 & 1 & 1 \\
\hline Married & 170 & 131 & $1.44(1.09-1.90)$ & $1.34(0.94-1.93)$ \\
\hline \multicolumn{5}{|l|}{ Salary (Daily as MSFW) } \\
\hline Low & 264 & 231 & $1.30(1.00-1.68)$ & $1.29(0.97-1.71)$ \\
\hline High & 213 & 242 & 1 & 1 \\
\hline \multicolumn{5}{|c|}{ Number of times have you been her } \\
\hline 1 times & 95 & 83 & $1.27(0.84-1.90)$ & $1.35(0.84-2.16)$ \\
\hline $2-4$ times & 146 & 147 & $1.10(0.77-1.58)$ & $1.19(0.78-1.80)$ \\
\hline $5-8$ times & 142 & 139 & $1.13(0.79-1.63)$ & $1.20(0.51-1.51)$ \\
\hline 9-30 times & 94 & 104 & 1 & 1 \\
\hline \multicolumn{5}{|c|}{ Length of time living here in the current visit } \\
\hline$<2$ months & 275 & 301 & $0.78(0.60-1.00)$ & $0.59(0.44-0.79)^{*}$ \\
\hline$>2$ months & 202 & 172 & 1 & 1 \\
\hline \multicolumn{5}{|c|}{ Using mass media (as source of information about malaria) } \\
\hline Yes & 231 & 97 & $3.64(2.73-4.84)$ & $2.25(1.52-3.32)^{*}$ \\
\hline No & 246 & 376 & 1 & 1 \\
\hline \multicolumn{5}{|c|}{ Using health workers (as source of information about malaria) } \\
\hline Yes & 298 & 211 & $2.07(1.56-2.68)$ & $0.84(0.60-1.20)$ \\
\hline No & 179 & 262 & 1 & 1 \\
\hline \multicolumn{5}{|c|}{ Using friends (as source of information about malaria) } \\
\hline Yes & 200 & 70 & $4.16(3.04-5.68)$ & $2.68(1.79-4.01)^{*}$ \\
\hline No & 277 & 403 & 1 & 1 \\
\hline \multicolumn{5}{|c|}{ Using schools (as source of information about malaria) } \\
\hline Yes & 99 & 46 & $2.43(1.67-3.54)$ & $1.30(0.80-2.01)$ \\
\hline No & 378 & 427 & 1 & 1 \\
\hline
\end{tabular}

* denotes an association where $p<0.05$ 
Table 4 Factors associated with good practice to prevent malaria among seasonal migrant farmworkers in Metema and West Armacheho districts, Northwest Ethiopia, 2018

\begin{tabular}{|c|c|c|c|c|}
\hline \multirow[t]{2}{*}{ Variables } & \multicolumn{2}{|c|}{ Practice } & \multirow{2}{*}{$\begin{array}{l}\text { COR with } \\
95 \% \mathrm{Cl}\end{array}$} & \multirow{2}{*}{$\begin{array}{l}\text { AOR with } \\
95 \% \mathrm{Cl}\end{array}$} \\
\hline & Good & Poor & & \\
\hline \multicolumn{5}{|l|}{ Age } \\
\hline $13-20$ & 46 & 198 & $0.53(0.37-0.78)$ & $0.51(0.33-0.80)^{*}$ \\
\hline $21-29$ & 147 & 338 & 1 & 1 \\
\hline $30-39$ & 46 & 105 & $1.00(0.97-0.68)$ & $0.74(0.45-1.19)$ \\
\hline $40-67$ & 19 & 51 & $0.86(0.49-1.50)$ & $1.19(0.61-2.35)$ \\
\hline \multicolumn{5}{|l|}{ Level of education } \\
\hline Unable to read and write & 80 & 294 & $0.55(0.31-0.82)$ & $0.74(0.39-1.40)$ \\
\hline Able to read and write & 22 & 51 & $0.80(0.42-1.53)$ & $0.7(0.31-1.67)$ \\
\hline Primary & 122 & 284 & $0.80(0.50-1.27)$ & $1.17(0.66-2.81)$ \\
\hline Secondary and above & 34 & 63 & 1 & 1 \\
\hline \multicolumn{5}{|c|}{ Length of time living here in the current visit } \\
\hline$<2$ months & 178 & 398 & $1.64(1.21-2.22)$ & $1.93(1.35-2.77)^{*}$ \\
\hline$>2$ months & 80 & 294 & 1 & 1 \\
\hline \multicolumn{5}{|c|}{ Using mass media as source of health information } \\
\hline Yes & 153 & 175 & $4.30(3.18-5.82)$ & $1.64(1.30-2.60)^{*}$ \\
\hline No & 105 & 517 & 1 & 1 \\
\hline \multicolumn{5}{|c|}{ Using health workers as source of health information } \\
\hline Yes & 186 & 323 & $2.95(2.16-4.02)$ & $1.06(0.67-1.68)$ \\
\hline No & 72 & 369 & 1 & 1 \\
\hline \multicolumn{5}{|c|}{ Using friends as source of health information } \\
\hline Yes & 142 & 128 & $5.39(3.95-7.36)$ & $2.55(1.61-4.02)^{*}$ \\
\hline No & 116 & 564 & 1 & 1 \\
\hline \multicolumn{5}{|c|}{ Using schools as source of health information } \\
\hline Yes & 61 & 84 & $2.24(1.55-3.23)$ & $0.74(0.44-1.36)$ \\
\hline No & 197 & 608 & 1 & 1 \\
\hline \multicolumn{5}{|l|}{ Knowledge } \\
\hline Good & 214 & 263 & $7.93(5.54-11.36)$ & $6.62(4.46-9.83)^{*}$ \\
\hline Poor & 44 & 429 & 1 & 1 \\
\hline \multicolumn{5}{|l|}{ Attitude } \\
\hline Favorable & 68 & 92 & $2.33(1.64-3.32)$ & $2.17(1.40-3.37)^{*}$ \\
\hline Un favorable & 190 & 600 & 1 & 1 \\
\hline
\end{tabular}

years but still it is low compared with other studies in Ethiopia among the general population [23, 24]. This finding is also consistent with similar study populations in Thailand, Pakistan and India [25-27]. The main possible reason for this significant difference is the nature of their working condition (they often work at night and sleep on the farmlands, in the area where they were harvesting, directly on the ground on the straw of the crop) [28]. The other possible reason might be low accessibility of ITNs, poor knowledge and negative attitude towards ITNs utilization.
WHO strongly recommends that every suspected malaria case must be tested and every confirmed case must be treated with anti-malarial drugs in malaria endemic areas [29]. But this study showed that only $22.8 \%$ of the participants had treatment seeking behavior. This is lower than a study conducted in Tigray (Ethiopia) among household level in the general population in which $32.1 \%$ of participants seek treatment within $24 \mathrm{~h}$ from the onset of the illness. However, this finding is similar to other study in Myanmar with similar study populations [30]. The possible reasons for this low treatment seeking behavior might be the remoteness of their 
worksites, inaccessibility of health facilities and antimalarial drugs, unaffordable cost charges [30] and selfmedication with antimalarial drugs [27]. The implication of this finding indicates that continuous and intensive behavior change communication campaigns should be planned and implemented for these high risk populations at the farming areas.

This study also revealed that knowledge and attitude is significantly associated with practice of malaria prevention. This finding was similar with other studies conducted in Ethiopia and Senegal among adult population at household level $[31,32]$. The implication of this finding is that, in order to increase ITNs utilization and other malaria prevention practices, we need to first increase the knowledge of malaria prevention methods and avoid misconceptions and wrong beliefs regarding the causes and prevention measures of malaria. Evidences also support the need of well-designed behavioral change programs to convert people's knowledge and attitudes into practice [33].

According to the results of this study, those study participants who had exposure for mass media had better knowledge and practice of malaria prevention. This finding is supported by a cross sectional study conducted in sub-Saharan African countries which showed participants who reported not receiving malaria related information from radio and poster/ billboards results in low knowledge and practice to prevent malaria [34]. John Hopkins communication center's malaria SBCC program also strongly supports the use of mass media in promoting malaria prevention and treatment behaviors [35]. The implication of this finding indicates that the Government's policy makers and stakeholders should design mass media intervention as an effective approach for these targeted populations at their departure site and mass transportation area.

The strength of this study was using large sample size which increase its generalizability to other similar study populations in Ethiopia while its limitation include lack of measuring the prevalence and the incidence rate of malaria due to lack of fund for laboratory equipment. The other limitation of this study was because of the nature of the cross sectional design, this study was unable to establish causality. Moreover, the study may be exposed for social desirability bias and recall bias because of the inclusion of different attitudinal and experience related questions.

\section{Conclusion}

In conclusion, the practice of malaria prevention among migrant and seasonal farm workers was low. Age, level of education, access to mass media and the length of stay in the farming site were factors significantly associated with the knowledge and practice of malaria prevention. Migrant and seasonal farm workers should be one of the priorities in the malaria prevention strategy in the country, and it is better to design and implement tailored malaria intervention programs and strategies for these hard to reach population.

\section{Abbreviations}

AOR: Adjusted odds ratio; Cl: Confidence interval; DALY: Disability adjusted life years; ITN: Insecticide treated nets; MSFWs: Migrant and seasonal farm workers; PSUs: Primary sample units; WHO: World Health Organization

\section{Acknowledgements}

The authors would like to thank the participants for volunteering to participate in the study.

\section{Authors' contributions}

GDD and KAG initiated the study concept and it was further enriched by TAA and SDW. HFW, MMS, TYA and DF participated in data collection, data analysis, and manuscript writing. All authors have read and approved the manuscript.

\section{Funding}

Not applicable.

\section{Availability of data and materials}

Data that support the findings are available from the correspondence author on reasonable request.

\section{Ethics approval and consent to participate}

Ethical clearance was obtained from the University of Gondar, Institute of Public Health, and a letter of permission from the district health office. An information sheet which clearly shows the research topic, the objectives of the study, confidentiality of the participants' responses, the study benefits and associated risks was prepared. Data were gathered after verbal consent was secured as of approximately $40 \%$ of the participants were illiterate and the ethics committee approved this procedure. The study participants' names and their other personal identifiers were not included to keep confidentiality. The collected data were also protected by password.

\section{Consent for publication}

Not applicable.

\section{Competing interests}

The authors declare that they have no competing interests.

\section{Author details}

${ }^{1}$ Department of Health Education and Behavioral Science, Institute of Public Health, University of Gondar, Gondar, Ethiopia. ${ }^{2}$ Department of Epidemiology and Biostatistics, Institute of Public Health, University of Gondar, Gondar, Ethiopia. ${ }^{3}$ Department of Environmental and Occupational Health and Safety, Institute of Public Health, University of Gondar, Gondar, Ethiopia.

Received: 19 June 2020 Accepted: 28 January 2021

Published online: 04 February 2021

References

1. WHO. World malaria report 2015: World Health Organization; 2016.

2. Howes RE, Battle KE, Golding N, Hay SI. Plasmodium vivax thematic review: epidemiology:: a thematic review prepared for the writing committee for the development of the WHO of global strategic plan on Plasmodium vivax control and elimination. Geneva: WHO; 2014.

3. Alemu K, Worku A, Berhane Y, Kumie A. Men traveling away from home are more likely to bring malaria into high altitude villages, northwest ethiopia. PLoS One. 2014;9(4)

4. Yukich J, Taylor C, Eisele T, Reithinger R, Nauhassenay H, Berhane $Y$, et al. Travel history and malaria infection risk in a low-transmission setting in Ethiopia: a case control study. Malar J. 2013;12(1):33.

5. Deressa W, Ali A, Berhane Y. Review of the interplay between population dynamics and malaria transmission in Ethiopia. Ethiop J Health Dev. 2006; 20(3):137-44. 
6. FDRE, MOH. Malaria diagnosis and treatment guidelines for Health Workers in Ethiopia,.AddisAbaba: 2004.

7. ANRSHB. Annual Report 2012-2013..Bahir Dar: 2013.

8. Chritz S, Yeshiwondim AK, Bansil P, Workie WM, Agma AA, Zeleke MT, et al., editors. Malaria control in migrant laborers working in agricultural farms in Metema Region, Ethiopia: Current practices, feasibility, and acceptability of new malaria interventions. Am J Trop Med Hyg. 2017. AMER SOC TROP MED \& HYGIENE 8000 WESTPARK DR, STE 130, MCLEAN, VA 22101 USA.

9. Lucas $A O$, Gilles HM. Short textbook of public health medicine for the tropics: CRC press; 2003

10. Aschale Y, Mengist A, Bitew A, Kassie B, Talie A. Prevalence of malaria and associated risk factors among asymptomatic migrant laborers in west Armachiho District, Northwest Ethiopia. Res Rep Trop Med. 2018;9:95.

11. Fuge TG, Ayanto SY, Gurmamo FL. Assessment of knowledge, attitude and practice about malaria and ITNs utilization among pregnant women in Shashogo District, Southern Ethiopia. Malar J. 2015;14(1):235.

12. Schicker RS, Hiruy N, Melak B, Gelaye W, Bezabih B, Stephenson R, et al. A venue-based survey of malaria, Anemia and mobility patterns among migrant farm workers in Amhara region, Ethiopia. PLoS One. 2015;10(11): e0143829.

13. Abate A, Degarege A, Erko B. Community knowledge, attitude and practice about malaria in a low endemic setting of Shewa Robit town, northeastern Ethiopia. BMC Public Health. 2013;13:312.

14. Astatkie A. Knowledge and practice of malaria prevention methods among residents of Arba Minch Town and Arba Minch Zuria District, Southern Ethiopia. Ethiop J Health Sci. 2010;20(3).

15. Ly P, Thwing J, McGinn C, Quintero CE, Top-Samphor N, Habib N, et al. The use of respondent-driven sampling to assess malaria knowledge, treatmentseeking behaviours and preventive practices among mobile and migrant populations in a setting of artemisinin resistance in Western Cambodia. Malar J. 2017;16(1):378

16. Girum T, Hailemikael G, Wondimu A. Factors affecting prevention and control of malaria among endemic areas of Gurage zone: an implication for malaria elimination in South Ethiopia. Trop Dis Travel Med Vaccines. 2017; 3(17)

17. Alelign A, Petros B. Knowledge, attitudes and practices of malaria transmission and preventive measures in Woreta town, Northwest Ethiopia. BMC Res Notes. 2018;11:491.

18. Bates I, Fenton C, Gruber J, Lalloo D, Medina LA, Squire SB, et al. Vulnerability to malaria, tuberculosis, and HIV/AIDS infection and disease. Part 1: determinants operating at individual and household level. Lancet Infect Dis. 2004;4:267-77.

19. Haile $M$, Lemma $H$, Weldu Y. Population movement as a risk factor for malaria infection in high-altitude villages of Tahtay-Maychew District, Tigray, northern Ethiopia: a case-control study. Am J Trop Med Hyg. 2017;97(3): 726-32.

20. Keating J, Macintyre K, Mbogo CM, Githure JI, Beier JC. Self-reported malaria and mosquito avoidance in relation to household risk factors in a Kenyan coastal city. J Biosoc Sci. 2005;37:761-71.

21. Ayanore M, Tetteh J, Ameko A, et al. Reproductive-age women's knowledge and care seeking for malaria prevention and control in Ghana: analysis of the 2016 malaria indicator survey. J Trop Med. 2019.

22. Musoke D, Karani G, Ssempebwa J, Etajak S, Guwatudde D, Musoke MB. Knowledge and practices on malaria prevention in two rural communities in Wakiso District, Uganda. Afr Health Sci. 2015;15(2).

23. Jima D, Getachew A, Bilak H, et al. Malaria indicator survey 2007, Ethiopia: coverage and use of major malaria prevention and control interventions. Malar J. 2010;9(58)

24. Tesfay K, Yohannes M, Mardu F, Berhe B, Negash H. Assessment of community knowledge, practice, and determinants of malaria case households in the rural area of Raya Azebo district, Northern Ethiopia. PLoS One. 2017;14

25. Wangroongsarb, et al. Respondent-driven sampling on the ThailandCambodia border. II. Knowledge, perception, practice and treatmentseeking behaviour of migrants in malaria endemic zones. Malar J. 2011; 10(117).

26. Qayum M, Zahur H, Ahmad N, llyas M, Khan A, Khan S. SPHERE-based assessment of knowledge and preventive measures related to malaria among the displaced population of Jalozai, Pakistan. JPMA J Pak Med Assoc. 2012;62(4):344
27. Yadav SP, Yadav S, Kuma P, Yadav S. Knowledge, treatment-seeking behaviour and socio-economic impact of malaria in the desert of Rajasthan India. Knowledge, treatment-seeking behaviour and socio-economic impact of malaria in the desert of Rajasthan, India; 2015.

28. Coulborn RM, Gebrehiwot TG, Schneider M, Gerstl S, Adera C, Herrero M, et al. Barriers to access to visceral leishmaniasis diagnosis and care among seasonal mobile workers in Western Tigray, Northern Ethiopia: A qualitative study. PLoS Negl Trop Dis. 2018;12(11).

29. WHO. WHO informal consultation on fever management in peripheral health care settings: A global review of evidence and practice. 2014.

30. Win AYN, Maung TM, Wai KT, Oo T, Thi A, Tipmontree R, et al. Understanding malaria treatment-seeking preferences within the public sector amongst mobile/migrant workers in a malaria elimination scenario: a mixed-methods study. Malar J. 2017;16(1):462.

31. Seck I, Fall I, Faye A, Ba O, Tal-Dia A. Malaria knowledge, attitudes and practices among women living in the rural area of Poponguine, Senegal. Med Trop. 2008;68(6):629-33.

32. Kebede DL, Hibstu DT, Birhanu BE, Bekele FB. Knowledge, Attitude and Practice Towards Malaria and Associated Factors in Areka Town, Southern Ethiopia: Community-Based CrossSectional Study. J Trop Dis. 2017;5(3).

33. Naing C, Whittaker MA, Tanner M. Inter-sectoral approaches for the prevention and control of malaria among the mobile and migrant populations: a scoping review. Malar J. 2018;17(1):1-7.

34. Yaya S, Uthman OA, Amouzou A, Bishwajit G. Mass media exposure and its impact on malaria prevention behaviour among adult women in subSaharan Africa: results from malaria indicator surveys. Glob Health Res Policy. 2018;3(1):20.

35. Health C. Capacity, collaborative., (HC3). Malaria SBCC evidence literature review. Baltimore: Johns Hopkins Center for Communication Programs; 2017.

\section{Publisher's Note}

Springer Nature remains neutral with regard to jurisdictional claims in published maps and institutional affiliations.

\section{Ready to submit your research? Choose BMC and benefit from:}

- fast, convenient online submission

- thorough peer review by experienced researchers in your field

- rapid publication on acceptance

- support for research data, including large and complex data types

- gold Open Access which fosters wider collaboration and increased citations

- maximum visibility for your research: over $100 \mathrm{M}$ website views per year

At BMC, research is always in progress.

Learn more biomedcentral.com/submissions 